\title{
Rhysacephala masneri sp. n. (Xiphydriidae), the first symphytan wasp recorded from Lord Howe Island
}

\author{
John T. Jennings ${ }^{\dagger}$, Andrew D. Austin ${ }^{\ddagger}$ \\ Australian Centre for Evolutionary Biology and Biodiversity, and School of Earth and Environmental Sciences, \\ The University of Adelaide, SA 5005, Australia. \\ † urn:lsid:zoobank.org:author:55C216C3-F90E-4670-81FD-93C6F36B9A37 \\ † urn:lsid:zoobank.org:author:DE71F924-750D-490D-84A7-F5960066F7CC \\ Corresponding author: John T. Jennings (john.jennings@adelaide.edu.au) \\ Academic editor: Norman Johnson | Received 06 March 2009 | Accepted 25 June 2009 | Published 14 September 2009 \\ urn:lsid:zoobank.org:pub:4E3D030D-EA64-4822-8AA1-1427EBEDC8DB \\ Citation: Jennings JT, Austin AD (2009) Rhysacephala masneri sp. n. (Xiphydriidae), the first symphytan wasp recorded \\ from Lord Howe Island. In: Johnson N (Ed) Advances in the systematics of Hymenoptera. Festschrift in honour of \\ Lubomír Masner. ZooKeys 20: 379-384. doi: 10.3897/zookeys.20.121
}

\begin{abstract}
Rhysacephala masneri sp. n. (Hymenoptera, Xiphydriidae), the first symphytan recorded from Lord Howe Island is described. Xiphydriid woodwasps are rarely collected in Australasia and the distribution of Rhysacephala, which is known from only seven described species from eastern Australia, New Guinea and New Caledonia, is significantly extended. We also discuss putative relationships among Australasian members of the genus.
\end{abstract}

\section{Keywords}

Rhysacephala, Xiphydriidae, Symphyta, woodwasp, oceanic island, Lord Howe Island

\section{Introduction}

Lord Howe Island, located approximately $770 \mathrm{~km}$ east of Australia and 1,350 km north-

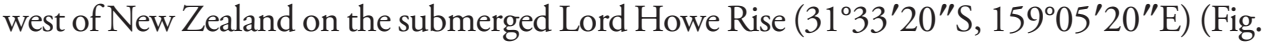
1 ), has captured the imagination of biologists for many decades. Apart from being one of the most picturesque islands in the south-west Pacific, Lord Howe is a true oceanic island (a 6.9 million-year-old extinct shield volcano; McDougall et al. 1981) and, because of its distance from surrounding continental landmasses, it has high levels of plant and invertebrate

Copyright J.T. Jennings \& A.D. Austin. This is an open access article distributed under the terms of the Creative Commons Attribution License, which permits unrestricted use, distribution, and reproduction in any medium, provided the original author and source are credited. 


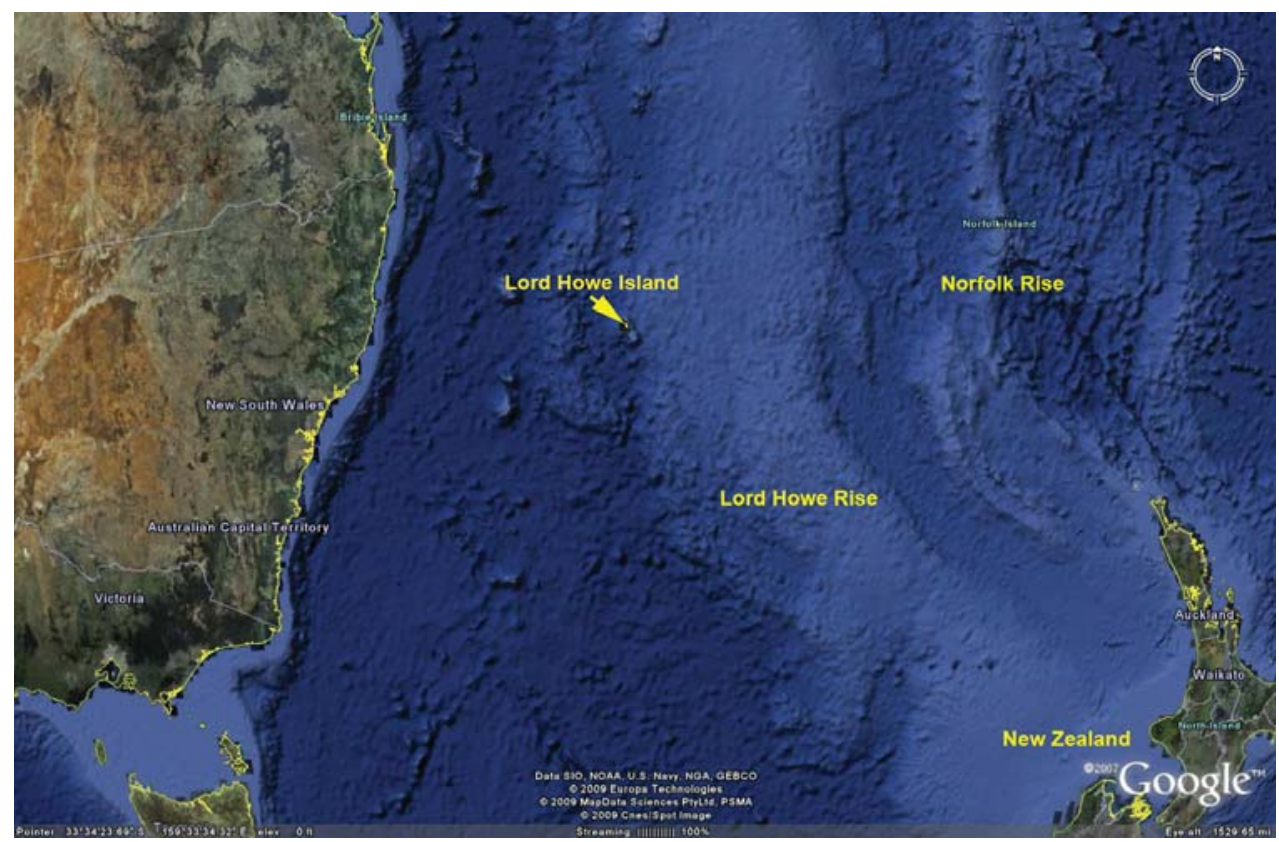

Figure I. Map showing the location of Lord Howe Island and Lord Howe Rise in relation to the Australian mainland and New Zealand (ex Google Earth - accessed Feb 2009).

endemicity (Cassis et al. 2003). Further, it has significant flora/habitat heterogenity for its $14.6 \mathrm{~km}^{2}$ area (Pickard 1983), largely because of the vertical relief provided by Mount Lidgbird $(777 \mathrm{~m})$ and Mount Gower $(875 \mathrm{~m})$ at the south end of the island.

Although numerous invertebrate surveys have been undertaken of the island over the last 50 years or so, the most comprehensive of which was run by the Australian Museum (Cassis et al. 2003), no sawflies (Symphyta) have previously been recorded, even though numerous species, particularly members of the mostly southern hemisphere family Pergidae, are found on the adjacent Australian mainland. Much rarer in Australasia are species of the worldwide family Xiphydriidae (except Africa; Smith 1978). They are represented in the region by only 11 described species in two subfamilies, Derecyrtinae and Xiphydriinae. Derecyrtinae are confined to South America except for Austrocyrta Riek from Australia (Riek 1955; Smith 1978; Jennings et al. 2007; 2009b). Xiphydriinae are worldwide in distribution (Smith 1978) and, in Australasia, there are nine described species; Rhysacephala leai (Forsius), $R$. obtusiventris (Rohwer), $R$. willsoni Benson and $R$. warraensis Jennings and Austin from Australia (Smith 1978; Jennings et al. 2009a), R. testacea (Mocsáry) from Papua New Guinea, $R$. rufipes (Smith) from the Aru Islands, Indonesia (Smith 1978), $R$. novacaledonicus Jennings \& Austin (Jennings et al. 2007) from New Caledonia, and Moaxiphia deceptus (Smith) and M. duniana (Gourlay) from New Zealand (Smith 1978).

Xiphydriid larvae are woodborers, have only vestigial legs (Smith 1978) and, in the Northern Hemisphere, develop in the wood of angiosperms, usually in small branches of deciduous trees such as Aceraceae, Betulaceae, Salicaceae and Ulmaceae (Smith, 
1978; Gauld and Bolton 1996; Smith and Schiff 2001), where they depend on symbiotic fungi in their tunnels. Very little is known about the biology of the Australasian xiphydriid fauna, although $R$. warraensis has recently been reared from a log of Anodopetalum biglandulosum (Cunoniaceae) in Tasmania (Jennings et al. 2009a). In New Zealand, the larvae of $M$. deceptus bore in twigs of the evergreen shrub Coprosma robusta (Rubiaceae), and the larvae of $M$. duniana bore in twigs of the evergreen southern beeches Nothofagus fusca and N. menziesii (Fagacae) (Valentine and Walker 1991).

Here we describe a new species of Rhysacephala from Lord Howe Island, the first record of a symphytan from the island. We also have much pleasure in describing this species after Lubomír Masner on the occasion of his $75^{\text {th }}$ birthday.

\section{Methods, terminology and abbreviations}

The specimen was examined and imaged under a Nikon DXM1200 stereomicroscope using Automontage software. Morphological terms generally follow Huber and Sharkey (1993), and terms for surface sculpturing follow Harris (1979). Collection abbreviation: ASCU - NSW Agricultural Scientific Collections Unit, Orange, New South Wales.

\section{Systematics}

Jennings et al. (2007) recently provided a discussion of and key to the xiphydriid genera of Australasia.

\section{Rhysacephala masneri sp. $\mathrm{n}$.} urn:Isid:zoobank.org:act:98F1DBCB-2F19-4E19-A34A-83DE9ECADDC9

Figs $1-4$

Type material: Holotype: female "Lord Howe Island, NSW. 18 Sept 1991. G.R. Brown”. ASCU - ASCT00026221.

Etymology. Rhysacephala masneri is named in honour of Lubomír Masner from the Canadian National Collection of Insects who is the world authority on the systematics of the parasitic wasp superfamilies Platygastroidea and 'Proctotrupoidea' s.l.

Diagnosis. Medium-sized species with head and antennae entirely black, 22 antennomeres, thorax and abdomen brown.

Description. Female: Length $7.7 \mathrm{~mm}$.

Colour. Head black, thorax and abdomen brown, antennae black, legs light brown; fore and hind wings infuscate.

Head. $1.34 \times$ as wide as long when viewed dorsally (Fig. 3); face and frons rugose, reticulate microsculpturing; vertex and gena reticulate; occipital carina narrow, almost absent medially; mandibles with 2 teeth; 22 antennomeres, scape $1.7 \times$ length pedicel, first flagellomere $1.1 \times$ length scape, $1.35 \times$ as long as second flagellomere. 


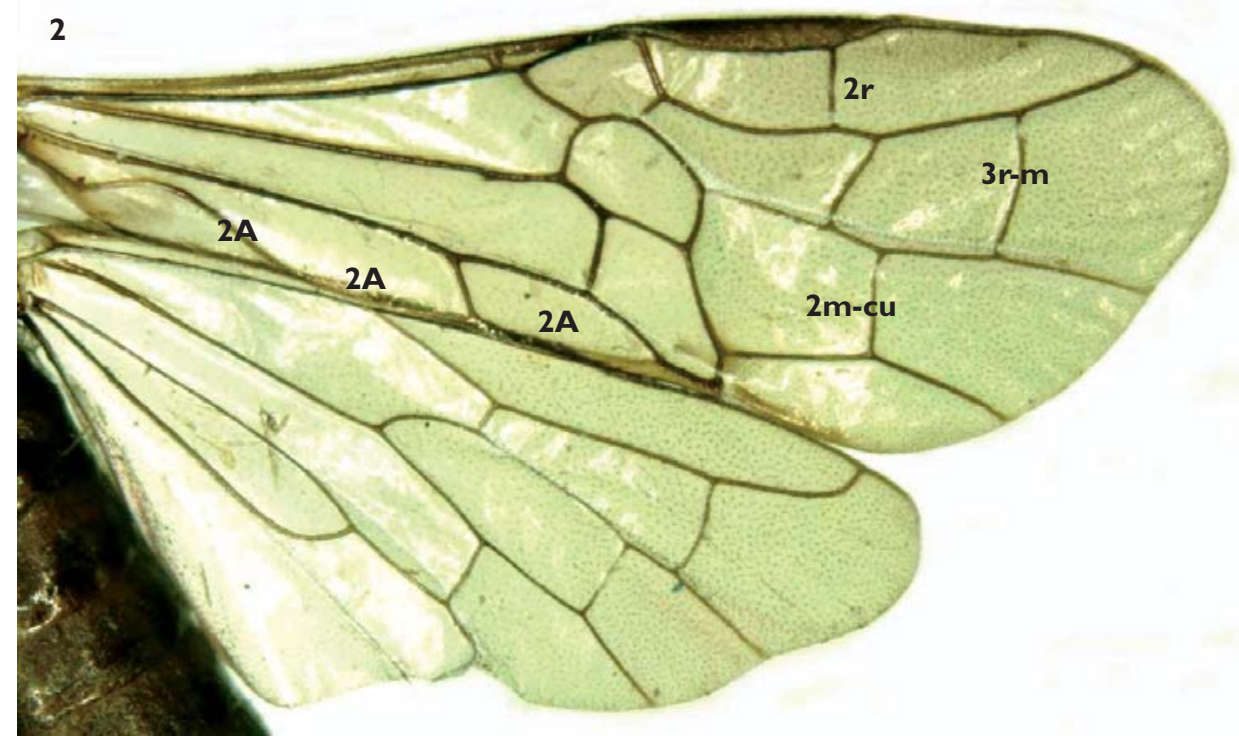

Figure 2. Right hand wings of $R$. masneri, holotype female. Fore wing $5.8 \mathrm{~mm}$ and hind wing $4.5 \mathrm{~mm}$ in length.
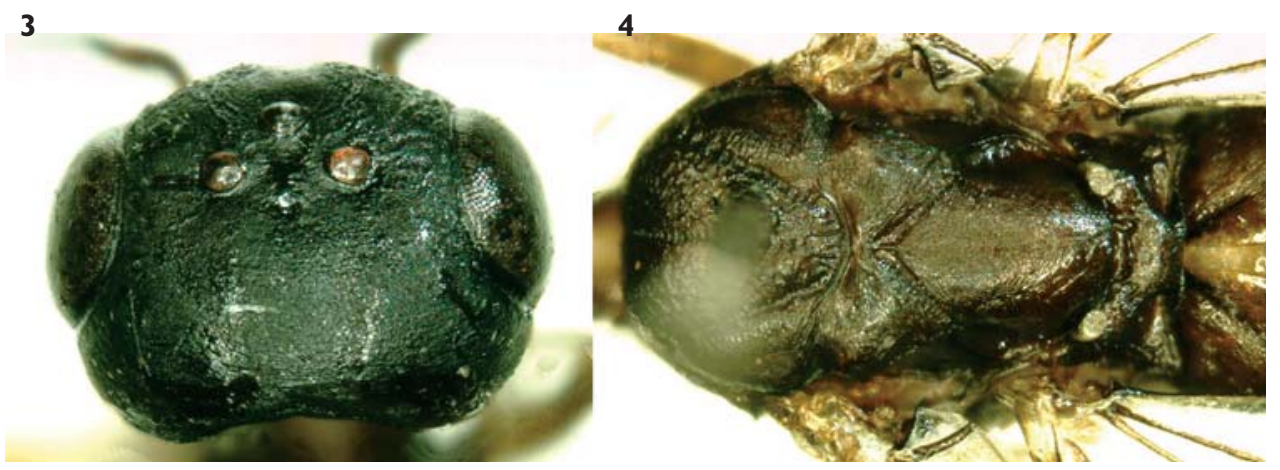

Figures 3-4. Dorsal head and thorax of R. masneri, holotype female. Head $1.2 \mathrm{~mm}$ in width; thorax $1.9 \mathrm{~mm}$ in length.

Thorax. Mesoscutum and metascutellum with reticulate microsculpturing, mesoscutum rugulose medially (Fig. 4); metapostnotum and mesepisternum with reticulate microsculpturing; mesepimeron broad, carinate; hind femur $0.7 \times$ length hind tibia; tibiae with two apical spurs, although inner one very short on fore tibia; basitarsus slightly longer than remaining segments combined.

Wings. Fore wing $5.8 \mathrm{~mm}$ in length (Fig. 2), vein $2 \mathrm{~A}$ becoming paler toward apex of vein, not reaching wing margin; hind wing $4.5 \mathrm{~mm}$ in length (Fig. 2), with 10 hamuli. Abdomen $2.2 \times$ length thorax.

Male Unknown. 
Remarks: This species lacks a prominent tubercle near the apex of the scutellum (Fig. 4) clearly placing it in the Xiphydriinae. It also has tarsal pulvilli which are absent in most Derycertinae (Benson 1954; Smith 1988).

Benson (1954) distinguished Rhysacephala from other Xiphydriinae by the presence of 7-segmented maxillary palps, the "fading out" of fore wing vein 2A (both character states shared with the New Zealand Moaxiphia) and several other character states which distinguish it from Moaxiphia, including parallel inner orbits of the eye and enlarged hind claws of female. Jennings et al. (2007) expanded the generic limits of Rhysacephala to accommodate $R$. novacaledonicus from New Caledonia which has the fore wing vein $2 \mathrm{~A}$ even in colouration. This species exhibits the general characteristics of Rhysacephala; the inner orbits of the eyes are more or less parallel, maxillary palps 7-segmented and, as in the majority of Rhysacephala, fore wing vein $2 \mathrm{~A}$ becomes pale towards the apex of the vein and does not reach the wing margin.

Rhysacephala masneri differs in colouration to all of the described species from Australia and New Caledonia. The head is entirely black as is the case for both $R$. wilsoni and $R$. obtusiventris. However, for both $R$. leai and $R$. novacaledonicus the head is black with a broad yellow stripe on the face, frons and gena near the margin of the eyes. In $R$. masneri, both the thorax and abdomen are brown, whereas in $R$. leai both the thorax and abdomen are pale reddish brown; in $R$. wilsoni the thorax is black and abdomen reddish brown, and in $R$. obtusiventris and $R$. novacaledonicus the thorax and abdomen are both black. Rhysacephala masneri is similar in length to $R$. novacaledonicus, but is intermediate in length to the Australian species; $R$. leai and $R$. wilsoni are both $9-10 \mathrm{~mm}$ long and $R$. obtusiventris is $5 \mathrm{~mm}$ long.

Distribution and occurrence: Rhysacephala masneri is known only from Lord Howe Island (Fig. 1). Nothing is known of its biology. We speculate that, given the recent origin of Lord Howe Island, it is likely that this species is derived from the Australian fauna; less likely is a New Caledonia origin.

Interestingly, $R$. masneri has not been recorded in the most detailed invertebrate survey of Lord Howe Island (Cassis et al. 2003). It may, for example, occur in a restricted habitat on the island and, if this habitat has not been sampled, then it may escape capture. The sampling methods used by Cassis et al. (2003) included pitfalls, litter and moss extraction, vegetation beating and hand collecting. These are probably not effective in collecting sawflies, or for that matter a broad range of Hymenoptera. The inclusion of other trapping techniques such as malaise traps and yellow pan traps in any future sampling regime might be appropriate. As well, adult sawflies are probably not long-lived and may easily be missed unless there is almost continuous sampling.

\section{Acknowledgements}

We thank Murray Fletcher, NSW Agricultural Scientific Collections Unit, Orange, NSW, for the loan of the specimen. We also thank the two anonymous reviewers who provided valuable comments on the manuscript. This work was carried out with funding support from an Australian Biological Resources Study grant. 


\section{References}

Austin AD, Jennings JT (2009) A bizarre new species of Spathius (Braconidae) from Lord Howe Island. Zookeys 20: 275-284.

Benson RB (1954) Classification of the Xiphydriidae (Hymenoptera). Transactions of the Royal Entomological Society, London 105: 151-162.

Cassis G, Meades L, Harris R, Reid C, Carter G, Wilkie L, Jeffreys E (2003) Lord Howe Island: terrestrial invertebrate biodiversity and conservation report. Australian Museum, Centre for Biodiversity and Conservation Research, $88 \mathrm{pp}$.

Gauld ID, Bolton B (Eds) (1996) The Hymenoptera. 2nd. Edition. Oxford University Press, Oxford, 332 pp.

Harris RA (1979) A glossary of surface sculpturing. Californian Department of Food and Agriculture, Bureau of Entomology, Occasional Papers 28: 1-28.

Huber JT, Sharkey MJ (1993) Structure, pp 13-59. In Goulet H, Huber JT (Eds) Hymenoptera of the World: An Identification Guide to Families. Research Branch, Agriculture Canada, Ottawa, 668 pp.

Jennings JT, Austin AD, Bashford R (2009a) First record of the woodwasp family Xiphydriidae from Tasmania with a description of a new species and host record. Australian Journal of Entomology 48: 25-28.

Jennings JT, Austin AD, Schiff NM (2007) Rhysacephala novacaledonicus sp. nov. (Hymenoptera: Xiphydriidae), the first xiphydriid woodwasp recorded from New Caledonia. Zootoxa 1516: 23-30.

Jennings JT, Austin AD, Schiff NM (2009b) The Australian endemic woodwasp genus Austrocyrta Riek (Hymenoptera: Xiphydriidae. Australian Journal of Entomology 48: 29-35.

McDougall I, Embelton BJ, Stone DB (1981) Origin and evolution of Lord Howe Island, southwest Pacific Ocean. Journal of the Geological Society of Australia 28: 155-176.

Pickard J (1983) Vegetation of Lord Howe Island. Cunninghamia 1: 133-265.

Riek EF (1955) The Australian Xiphydriidae (Hymenoptera: Symphyta). Australian Journal of Zoology 3: 281-285.

Smith DR (1978) Hymenopterorum catalogus. Ed. van der Vecht J. \& Shenefelt, R.D. Pars 14: Suborder Symphyta (Xyelidae, Pararchexyelidae, Parapamphiliidae, Xyelydidae, Karatavitidae, Gigasirididae, Sepulcidae, Pseudosiricidae, Anazyelidae, Siricidae, Xiphydriidae, Paroryssidae, Xyelotomidae, Blasticotomidae, Pergidae). W. Junk, The Hague.

Smith DR (1995) A new species of Xiphydriidae (Hymenoptera) from Chile. Revista Chilena de Entomología 22: 21-24.

Smith DR, Schiff NM (2001.) A new species of Xiphydria Latreille (Hymenoptera: Xiphydriidae) reared from river birch, Betula nigra L., in North America. Proceedings of the Entomological Society of Washington 103: 962-967.

Valentine EW, Walker AK (1991) Annotated catalogue of New Zealand Hymenoptera. DSIR Plant Protection Report No. 4, DSIR, Auckland, 84 pp. 